\title{
Ensayo autobiográfico en diálogo con Prof. Rafael Capurro ${ }^{1}$
}

Agradeciendo la presencia de todos los profesores y estudiantes, presento a aquellos que no tuvieron ayer la ocasión de conocer al profesor Capurro, uno de los teóricos de nuestra área a quien hoy tenemos el gran placer de recibir en nuestra escuela de Pos-graduación, y con quien los estudiantes posgraduados y profesores están invitados a conversar. En consecuencia, no se ha previsto hoy ninguna dinámica ni conferencia específica, ya que ayer en la conferencia de conmemoración no se abrió ningún espacio para el debate. Este puede ser el foro para comentar o preguntar aquello para lo que ayer no hubo ocasión. En la charla informal que ahora mantendremos con el Profesor Capurro pueden poner sobre la mesa lo que ayer quedó en el tintero.

Iré anotando la secuencia de las intervenciones solicitadas para que en el orden correspondiente puedan dialogar con el profesor. Tratándose de un teórico y autor destacado en el campo que ustedes estudian, se trata de una -sin duda- excelente oportunidad para conversar acerca de cuestiones que les inquieten.

Pero antes, y para abrir el espacio en el que luego se desenvuelva la conversación, ¿Sería tan amable -Profesor- de hablarnos acerca de su trayectoria investigadora, sus ideas y lo que ha hecho recientemente?

Por favor llámame Rafael. Disculpen que hable en castellano y no en portugués. Mejor un buen castellano que un mal portugués. Ustedes vieron ayer la temática en la que me muevo profesionalmente, mi pasado está enraizado en las ciencias de la información.

En el año 1972 me dirigí a Alemania para estudiar Documentación en el "Instituto de Documentación" ("Lehrinstitut für Dokumentation" LID) de Frankfurt. Internet no se había inventado. Era otro mundo. Las ciencias de la documentación estaban centradas en el "information retrieval".

(Pausa para mejora en el audio)

Había una tensión entre la documentación, llamada luego ciencia de la información, y la biblioteconomía. Tensión es una metáfora, había odios, incomprensiones y demás. Eso duró muchos años tanto a nivel académico como a nivel práctico.

Nací en Montevideo en 1945 de familia uruguaya descendientes de italianos, vascos y españoles. ${ }^{2}$ Mi padre, Mario Capurro Etchegaray, era ingeniero agrónomo, casado con Raquel Fonseca Piaggio, mi madre, y en segundas nupcias, luego de la temprana muerte de mi madre, con su hermana Matilde. Somos nueve hermanos, dos del primer matrimonio y

\footnotetext{
${ }^{1}$ Agradezco al José María Díaz Nafría (Universidad de León, España) por su gentileza de haber revisado cuidadosamente este texto.

${ }^{2}$ Ver http://www.capurro.de/capurro etchegaray.html y http://www.capurro.de/jbcapurro.html
} 
siete del segundo. Estudié filosofía en el "Colegio Máximo de San Miguel" (Universidad del Salvador, Argentina) ${ }^{3}$ y anteriormente griego, latín, retórica, literatura e historia del arte en Chile ${ }^{4}$ como miembro de la orden de los Jesuítas. Hice la licenciatura en filosofía y dejé los Jesuítas en 1970. Trabajé un año en el centro de documentación de una comisión científica en Buenos Aires cuyo director tenía buenas relaciones con Alemania. Yo había estudiado alemán en el colegio de los Hnos. Maristas en Montevideo que profundicé luego durante mis estudios de humanidades y filosofía.

En el marco de intercambio científico entre la Argentina y Alemania se me dió la oportunidad de venir a Alemania a estudiar documentación en el "Centro de documentación en energía nuclear" ("Zentralstelle für Atomkernenergie-Dokumenation", ZAED) donde se creaba una base de datos bibliográfica y que pertenecía al "Centro de investigación en energía nuclear" ("Kernforschungszentrum Karlsruhe") ubicado cerca de la ciudad de Karlsruhe. ${ }^{5}$ Dicha base de datos era la contribución nacional al "International Nuclear Information System" (INIS) coordinado hasta hoy por la "International Atomic Energy Agency" (IAEA) en Viena. ${ }^{6}$ Este sistema de intercambio internacional, al que contribuía también la Unión Soviética, permitía al Occidente enterarse de lo que se investigaba en Europa del Este en este campo tan sensible en el plano político y militar. INIS fue uno de los primeros sistemas bibliográficos donde se aplicaron modernas técnicas de documentación basadas en la computación. Después de dos años tendría que haber vuelto a Buenos Aires pero hubo problemas políticos por el retorno de Perón a Buenos Aires y me quedé en Alemania. Me casé y trabajé dos años en ese centro de documentación.

Alrededor de 1975 comencé a interesarme filosóficamente por el tema ¿qué es información? Tenía contactos con el departamento de filosofía de la Universidad de Düsseldorf donde el professor Norbert Henrichs creaba una base de datos bibliográfica en filosofía. En aquella época el concepto de información no era interesante para los filósofos. Nadie podía imaginarse que este iba a ser un concepto filosófico clave. Impulsado por la pregunta que surgía desde mi ámbito laboral me dije ¿por qué no hacer un estudio filosófico sobre este concepto? Trabajé en este tema dos años bajo la dirección del profesor Henrichs y me doctoré con una tesis histórica sobre la evolución del término información que se publicó en 1978 y que es ahora accesible en la red. ${ }^{7}$

En Alemania la relación entre filosofía y documentación no era muy importante siendo los professores Norbert Henrichs y Alwin Diemer, quien era director del instituto, de los pocos filósofos que se interesaban por este tema. (10 minutos) Las cuestiones éticas surgieron en la década de 1970. Los primeros artículos sobre ética de la información fueron publicados por Stephan Schwarz, director de la "Royal Institute of Technology Library" de Estocolmo en 1979 y Barbara Kostrewski y Charles

\footnotetext{
${ }^{3}$ Ver http://www.facultades-smiguel.org.ar/inicio.html

${ }^{4}$ Ver: http://www.espiritualidad-sj.winper.cl/Obra-CEL.php

${ }^{5}$ Ver http://www.fzk.de/fzk/idcplg?IdcService=FZK

${ }^{6} \mathrm{Ver}$ http://www.iaea.org/inis/About us/history.htm

${ }^{7}$ Ver http://www.capurro.de/info.html
} 
Oppenheim en Inglaterra en 1980, pero sin olvidar la obra de pioneros como Norbert Wiener y Joseph Weizenbaum. Yo utilicé el término "ética de la información" ("Informationsethik") por primera vez en un artículo publicado en $1981^{8}$ inspirado por el diálogo con el profesor Henrichs quien me orientaba en lo que sería mi tesis de posgrado ("Habilitation") "Hermenéutica de la información especializada" ("Hermeneutik der Fachinformation"), publicada en 1986. En 1985 Stephan Schwarz me invitó a dar dos conferencias sobre el concepto de información desde un punto de vista epistemológico ${ }^{9}$ ético. ${ }^{10}$

A fines de la década de 1970 el ZAED fue transformado en un gran centro de información científico-técnica ("Fachinformationszentrum Karlsruhe", FIZ Karlsruhe). Entre 1980 y 1985 trabajé en el FIZ como asistente del director científico. Esto me dió oportunidad de contactos internacionales por ejemplo con China y Japón y por supuesto con los Estados Unidos - el FIZ creó en 1977 junto con Chemical Abstract Service (CAS) y el "Centro japonés de información" una de las primeras redes científicas internacionales (STN International). ${ }^{11}$

Luego de estos seis años me presenté a un concurso para una cátedra en la "Escuela de Biblioteconomía" ("Fachhochschule für Bibliotekswesen" FHB) de Stuttgart, que luego se transformaría en la "Escuela de Biblioteconomía e Información" ("Hochschule für Bibliotheksund Informationswesen", HBI) y finalmente en la "Universidad de los Medios" ("Hochschule der Medien" HdM). ${ }^{12}$ En la FHB el interés por la documentación era mínimo y se lo veía como algo suplementario o incluso meramente marginal sobre todo para las bibliotecas públicas que constituían el núcleo de dicha escuela. Alrededor del año 1995 explotó la bomba Internet. Entre tanto las Ciencias de la Información iban cambiando muy rápidamente y se iban separando cada vez más de la biblioteconomía tanto a nivel académico como laboral. Se crearon algunas cátedras universitarias como por ejemplo la del professor Rainer Kuhlen en la Universidad de Konstanz o la de Gernot Wersig en en la "Freie Universität" de Berlín. La "Sociedad Alemana de Documentación" ("Deutsche Gesellschaft für Dokumentation" DGD) que luego se denominó "Sociedad Alemana para la ciencia y la práctica de la información" ("Deutsche Gesellschaft für Informationswissenschaft und Informationspraxis" DGI) ${ }^{13}$ estaba más interesada en problemas prácticos, lo cual llevó a la creación de una "Red Universitaria para la Ciencia de la Información", obra sobre todo de Rainer Kuhlen ("Hochschulverband für Informationswissenschaft"). ${ }^{14}$

\footnotetext{
${ }^{8}$ Ver http://www.capurro.de/infoethik81.html

${ }^{9}$ Ver http://www.capurro.de/trita.htm

${ }^{10}$ Ver http://www.capurro.de/moral.htm

${ }^{11}$ Ver http://www.stn-international.de/index.php?id=123

${ }^{12}$ Ver http://www.hdm-stuttgart.de/hochschule/

${ }^{13}$ Ver http://www.dgd.de/home.aspx

${ }^{14}$ Ver http://www.informationswissenschaft.org/index.html
} 
El desarrollo de la ciencia de la información en Alemania no tuvo mucho éxito. Una razón fue la estructura federal de la política cultural alemana que no hacía posible la creación sistemática de cátedras universitarias en este campo a pesar del interés político en la documentación desde 1974. Otra razón fue la falta de conexión entre la biblioteconomía, la ciencia de la información y la informática a diferencia de la "Library and Information Science" (LIS) en Estados Unidos. Los pocos colegas que se dedicaban a la ciencia de la información provenían de diversas disciplinas, como ser la filosofía, la sociología, el periodismo o la lingüística de modo que la joven disciplina no tenía un perfil claramente definido más allá del information retrieval. Además de los congresos académicos organizados por la la Red Universitaria recién mencionada, se celebraron también congresos de carácter más práctico organizados por la DGI. Ambos grupos nacieron y se desarrollaron institucionalmente separados de la biblioteconomía. En la década de 1980 los informáticos alemanes comenzaron a interesarse por la dimensión social de su disciplina y crearon un "Foro de informáticos para la paz y la responsabilidad social" ("Forum InformatikerInnen für Frieden und gesellschaftliche Verantwortung" FifF). ${ }^{15}$ Además se crearon cátedras de "Informática y Sociedad".

En la década del 90 vino Internet y el panorama cambió totalmente debido al enorme impacto social de la red. Al comienzo se idealizó el cyberspace como una dimensión casi sagrada que permitiría una existencia más allá de las estructuras políticas y sobre todo de la sociedad industrial. Un ejemplo de lo que podríamos llamar cibergnosis es la "Declaración de la independencia del ciberespacio" (1996) de John Perry Barlow $^{16}$ una especie de sueño semiteológico de redención digital del individuo y de la humanidad a la que apunta el término teológico de gnosis y del que hay adeptos también hoy en día.

La bomba Internet estalló en Alemania en un ambiente filosófico muy particular. Por un lado un rechazo de la tradición clásica filosófica germana y una adhesión a la filosofía analítica que venía de los Estados Unidos. Se produjo entonces algo curioso ya que en los Estados Unidos tuvo lugar una recepción de la fenomenología y la hermenéutica (Ihde, Borgmann) así como de autores franceses (Derrida, Lyotard, Foucault) e italianos (Vattimo). Heidegger era y sigue siendo interpretado en Alemania de forma muy crítica, lo cual es comprensible debido a las experiencias traumatizantes del nazismo, el holocausto y la segunda guerra mundial. Predominaban además desde la década de 1970 el Racionalismo Crítico de Karl Popper y las escuelas de pensamiento lideradas por Jürgen Habermas, con la teoría de la acción comunicativa, y la teoría de sistemas de Niklas Luhmann con conexiones a corrientes constructivistas. Los seguidores de Luhmann y Habermas formanban dos bandos - algo semejante a lo que pasó con la oposición entre los

\footnotetext{
${ }^{15}$ Ver http://www.fiff.de/

${ }^{16}$ Ver http://es.wikisource.org/wiki/Declaraci\%C3\%B3n_de_independencia_del_ciberespacio
} 
seguidores del Racionalismo Crítico de Popper y los de la hermenéutica de Gadamer - en los que se defendía o se criticaba al sujeto clásico occidental. Este parecía perder su base unificadora racional propagada por Habermas y se desmembraba en distintos sistemas sin que fuera posible crear un meta-observador. A esto se sumaba la semiótica, el sicoanálisis, los planteamientos ecológicos, diversos autores de las corrientes posmodernas y otras corrientes derivadas de la Escuela de Frankfurt y del constructivismo.

Mi formación filosófica estaba enraizada en la fenomenología (Husserl, Heidegger) y la hermenéutica (Gadamer), dándose en mi modo de pensar y vivir algo así como una separación entre esta formación académica y los temas técnicos y profesionales en torno a la información y la computación. Fue y sigue siendo mi intención el superar este dualismo tratando de buscar aproximaciones filosóficas de las nuevas tecnologías. Este fue el impulso que me llevó a escribir las tesis de doctorado y posdoctorado así como muchos artículos y libros sobre todo a partir de 1986 cuando empecé a trabajar en la "Escuela de Biblioteconomía" de Stuttgart. ${ }^{17}$

La percepción de la computación como algo que influenciaba cada vez más a la sociedad y al pensamiento fue algo que fui descubriendo paulatinamente. Hay un dicho que se le atribuye a Hegel pero también a Victor Hugo, Voltaire y Pascal: 'no hay nada más poderoso en el mundo que una idea cuyo tiempo ha llegado' ("Rien n'arrête une idée dont le temps est venu" V. Hugo). Esta idea es, según creo, la de la comprensión de la realidad o del ser en el horizonte digital. Comprendemos lo que las cosas son cuando somos capaces de digitalizarlas. Se trata de una tesis epistemológica u ontológica, en términos heideggerianos, no metafísica.

El mundo en el que vivimos está condicionado por la interpretación digital del ser de los entes. No sólo las corrientes filosóficas alemanas derivadas de la fenomenología y la hermenéutica sino también otras escuelas como las anteriormente mencionadas se mostraron reticentes frente al desafío computacional, en algunos casos por una aversión casi innata con relación a la técnica en general y a la computación en particular. Pero sin embargo no olvidemos que Heidegger fue uno de los grandes pensadores de la técnica mientras que su alumno Gadamer y la mayoría de sus sucesores no supieron o quisieron relacionar la hermenéutica con la computación y su auge en especial a partir de la década de 1970. Recordemos también la crítica a la cultura de masas de los pensadores de la Escuela de Frankfurt desde Adorno hasta Habermas. Mi tesis de posdoctorado fue un intento de superar esta alienación entre, por un lado, la hermenéutica y el pensamiento filosófico en general y la computación por el otro, llevando a lo que hoy se denomina "filosofía y computación" y también "filosofía de la información".

\footnotetext{
${ }^{17}$ Ver: http://www.capurro.de/publi.htm
} 
Estos debates filosóficos tuvieron relativamente poca influencia en la ciencia de la información durante las décadas del 70 y 80 . Eran dos culturas, recordando a C. P. Snow, que se ignoraban mutuamente. Recién a fines de 1990, luego del invento del World Wide Web y otros servicios sociales en Internet, comenzó a despertarse el interés por la ética de la información. Este interés me llevó a crear en 1999, siguiendo la sugerencia de mi colega Wolfgang von Keitz, una comunidad virtual, algo entonces poco común, a la que denominé "International Center for Information Ethics" (ICIE). Había poco interés en este tipo de comunidades conectadas con una mailing list $y$ un sitio web. ${ }^{18}$ Yo trabajaba en este campo en la escuela de Stuttgart que en estos años se transformó en la "Universidad de los Medios" ("Hochschule der Medien" $\mathrm{HdM})^{19}$ que no ha de confundirse con la Universidad de Stuttgart donde yo también enseñaba Filosofía Práctica (Ética), luego de haber defendido con éxito mi tesis de postdoctorado en $1989 .{ }^{20}$

Encontré apoyo temprano a mi interés por problemas éticos de la información sobre todo en colegas estadounidenses (Thomas Froehlich, Marta Smith) y canadienses (Bernd Frohmann). EI ICIE fue creciendo muy rápidamente gracias al apoyo del Dr. Felix Weil ${ }^{21}$ quien me ofreció también su ayuda para crear la revista "International Review of Information Ethics" (IRIE) en 2004. ${ }^{22}$ El prestigioso "Centro para Arte y Tecnología de los Medios" de Karlsruhe ("Zentrum für Kunst und Medientechnologie" ZKM) ${ }^{23}$ me ofreció hospitalidad para el ICIE así como para diversos congresos y meetings. También se unieron a este proyecto colegas de la Universidad de Augsburgo, en particular Thomas Hausmanninger, con quien organicé los primeros congresos del ICIE y con quien inicié la serie de libros del ICIE en la editorial Fink de Munich. ${ }^{24}$

Uno de los puntos culminantes de los últimos diez años fue ciertamente el congreso sobre aspectos interculturales de la ética de la información en 2004 en Karlsruhe, patrocinado por la Fundación Volkswagen. ${ }^{25}$ Fue el primer congreso dedicado a lo que ahora se llama ética intercultural de la información. Participaron unos 50 colegas de todo el mundo, estando África muy mal representada por falta de contactos con colegas de ese continente. Pocos años después, en 2007, pudimos organizar con el apoyo del gobierno de Sudáfrica, el patrocinio de la UNESCO y la colaboración y el entusiasmo de muchos colegas africanos, en especial de Johannes Britz (University of Pretoria y University of Wisconsin-Milwaukee), el "Primer Congreso Africano de Ética de la

\footnotetext{
${ }^{18}$ Ver http://icie.zkm.de

${ }^{19}$ Ver http://www.capurro.de/lehre.html\#FH_Stuttgart

${ }^{20}$ Ver http://www.capurro.de/lehreuni.htm

${ }^{21}$ Ver http://www.quibiq.de/

${ }^{22}$ Ver http://www.i-r.i-e.net

${ }^{23}$ Ver http://www.zkm.de/

${ }^{24}$ Ver http://icie.zkm.de/publications/books

${ }^{25}$ Ver http://icie.zkm.de/meetings
} 
Información" que tuvo lugar en Pretoria así como la "Africa Network for Information Ethics" (ANIE). ${ }^{26}$ El segundo congreso tendrá lugar en Gaborone (Botswana) el 6-7 de setiembre de 2010.

En América Latina creamos gracias al entusiasmo de Miguel Angel Pérez Alvarez la "Red Latinoamericana de ética de la información" (RELEI) ${ }^{27}$ Del 1 al 4 de marzo de 2011 tendrá lugar en la Universidad del Claustro de Sor Juana en Ciudad de México el Segundo Congreso Latinoamericano de ética de la información. Como ustedes saben, fue también gracias al entusiasmo de colegas como Gustavo Freire, AnaThereza Dürmaier, Isa Freire, Edvaldo Carvalho y muchos otros, que se pudo organizar en la Universidad Federal de Paraiba el I Simpósio Brasileiro de Ética da Informação del 18 al 19 de marzo de $2010 .^{28}$

A nivel teórico...[interrupción para pregunta.]

... a la banca que eu queria muito ouvir sobre a ... da informação e esse seu histórico na área e muito rico para mostrar como a situação de ciência tem passado muito em forma fragmentada, em forma hibrida com poça identificação que para a gente esta claro. Eu estou interrompendo porque eu vou participar de aulas agora e gostaria muito de ouvir como você vê esta edição da nossa área que a gente esta sempre falando que e uma ciência nova ... Mas nós estamos progredindo estou chegando da França eu chegue ontem, teve uma reunião lá nem conheciam, o que apresente nem o ano passado para eles também e tal, nossa área e muito fragmentado, dentro de cada pais y estamos fragmentados no mundo também a influencia que tem da poli que e documentação, que e biblioteconomia, etc. ... Documentação aqui.... colado com comunicação e então eu queria ouvir sobre isso, como que você vê essa questão da nova área?

¿A nivel práctico, a nivel académico practico o a nivel teórico?

Não a nível teórico eu acho que você não tem uma identidade teórica evidentemente em forma pratica vai repercutir.

La confluencia entre la hermenéutica, la teoría de sistemas y la técnica digital ofrece, a mi modo de ver, una oportunidad para pensar una ciencia de la información diferente a la tradicional centrada en las técnicas del information retrieval. Lo que yo llamo "ontología digital" es un proyecto de interpretación de la realidad en que vivimos condicionada por la computación. Los orígenes de dicha ontología se remontan a un diálogo email con el filosófo australiano Michael Eldred. ${ }^{29}$ (39:00)

\footnotetext{
${ }^{26}$ Ver http://www.africainfoethics.org/index.html y también http://icie.zkm.de/africainfoethics. Para una visión detallada de las actividades recientes ver http://www.capurro.de/wsis2010_africa_infoethics.html

${ }^{27}$ Ver http://redeticainformacion.ning.com/

${ }^{28}$ Ver http://dci.ccsa.ufpb.br/sbei/

${ }^{29} \mathrm{Ver}$ http://www.capurro.de/digont.htm
} 
Desde la publicación de mi tesis doctoral sobre el concepto de información en 1978 he buscado diversos caminos para pensar dicho concepto. Uno de ellos está conectado con la teoría de sistemas de Niklas Luhmann, quien define el concepto de comunicación en base a tres dimensiones. La primera es la "oferta de sentido" que él Ilama "Mitteilung", un término que en alemán es sinónimo al de información ("Information") y al que yo llamo mensaje. Luhmann distingue entre mensaje ("Mitteilung") e información ("Information") siendo esta última el proceso de selección entre los posibles sentidos de un mesnaje. La tercera dimensión es la "comprensión" ("Verstehen") o sea la integración de la selección hecha en el sistema que la realiza. Esta última es el tema de la hermenéutica entendida tanto clásicamente como teoría de la comprensión de textos como en el sentido de la hermenéutica existencial de Heidegger y Gadamer como auto-comprensión del ser-en-el-mundo. Creo que estos tres momentos conceptuales pensados en su mutua relación, pueden servir de fundamento para una ciencia de la información nueva y relacionada no sólo con la hermenéutica sino también con lo que yo llamo "angelética" o teoría de los mensajes/mensajeros. ${ }^{30}$ La ciencia de la información es entonces un punto de pasaje entre hermenéutica, angelética y computación. La filosofía de la información, propagada actualmente por diversos autores, encuentra en la ontología digital un posible fundamento. (42:11).

El sistema comunicacional creado por Internet cuestiona la estructura jerárquica de los medios de comunicación de masas vigentes hasta fines del siglo XX con sus monopolios de diseminación de mensajes y mensajeros. Gracias a Internet todo receptor de un mensaje puede transformarse sin grandes dificultades técnicas o económicas en un emisor más allá de la relación uno-a-uno creada por el teléfono en su forma original. A nivel filosófico creo que un sistema que, por utilizar un término de Gianni Vattimo, "debilita" las estructuras de comunicación jerárquicas y sus centros de poder lleva a concebir otro tipo de subjetividad y sociedad a la que se creó tanto con la cultura del libro en la época de la Ilustración o con los medios de comunicación de masa en el siglo XX.

Esto nos lleva a discutir la problemática del humanismo. Hay una crisis del humanismo frente a los desarrollos tecnológicos que provoca a veces mucha angustia o incertidumbre a nivel social, político y legal en especial cuando las sociedades están basadas en una concepción antropocéntrica (a menudo 'androcéntrica') del mundo que es en parte fruto de una reacción frente a los horrores de la segunda guerra mundial. (50:00) Somos un producto de la evolución y estamos emparentados genéticamente con los monos así como con diversas familias de hominidos lo que cuestiona una separación tajante entre el hombre y el animal como la hacía la filosofía clásica occidental. Algunas corrientes de pensamiento del Lejano Oriente nos ofrecen un legado de relaciones más íntimas y positivas entre hombre y naturaleza. Conceptos como los de autonomía, dignidad humana o libertad deberían pensarse en conjunción con los de

\footnotetext{
${ }^{30}$ Ver http://www.capurro.de/tsukuba.html. Ver también http://www.capurro.de/db.htm
} 
interacción, dependencia, cuidado por los seres vivientes no-humanos, solidaridad y responsabilidad por el mundo que dejamos a las generaciones futuras. En este contexto, la tecnología digital juega un rol central también en conjunción con la biología permitiendo no sólo muchas formas de intervención y 'mejoramiento' ('enhancement') - pero también de un posible 'empeoramiento' - de capacidades humanas sino también de diseño de seres vivientes como lo preconiza la biología sintética. ${ }^{31} \mathrm{Si}$ bien Internet ha revolucionado el sistema comunicacional a nivel planetario las consecuencias con respecto a su impacto a nivel cultural e inter-cultural son todavía difíciles de evaluar y constituyen un tema importante de una futura ciencia de la información y de la actual ética de la información. ${ }^{32}$ (54:00)

Las repercusiones en la autocomprensión humana son de gran envergadura. Surgen profetas que preconizan un 'transhumanismo'. Los desafíos naturalistas y tecnicistas hacen virulenta una discusión sobre el humanismo pero de forma diferente a como se planteó en la posguerra si uno piensa, por ejemplo, en "L'existentialisme est un humanisme" (1945) de Sartre o en la "Carta sobre el 'humanismo'" (1946) de Heidegger. La discusión actual está condicionada, a mi parecer, tanto por el problema ecológico como por la técnica digital y tiene dimensiones globales en un difícil diálogo intercultural que recién ha acomenzado. Dicho diálogo está centrado hasta ahora en temas de bioética pero se va abriendo también al impacto de la tecnología digital. Esta abarca desde los implantes digitales, pasando por manipulaciones genéticas hasta las posibles configuraciones de futuras sociedades de la información y de sus sustentos materiales que generan ya un serio problema de 'basura digital' ('e-waste') con consecuencias ecológicas y de justicia social de gran envergadura.

Si bien somos, genéticamente hablando, UNA humanidad esto no es, creo, un fundamento suficiente para postular éticamente por ejemplo el derecho humano a la diversidad cultural ni tampoco para el respeto no sólo a nuestros parientes cercanos o lejanos y a nuestra relación con la naturaleza misma. Si postulamos un derecho humano a la diversidad cultural también lo hacemos con respecto a la biodiversidad. Si bien somos UNA humanidad somos también 'humanidades' en el doble sentido que tiene este término en español y en inglés, donde las 'humanidades' o las 'humanities' son las ciencias humanas en cuanto que ciencias de lo humano en toda su amplitud y variabilidad de etnias, lenguas, culturas y visiones del mundo.

Esta universalidad y diversidad de los conceptos la expresa la filosofía occidental desde Platón con el concepto de forma ('idea', 'eidos') que es el origen etimológico y conceptual de nuestro actual concepto de información a través del término latino 'informatio'. A esta historia está dedicada mi tesis doctoral ya mencionada así como investigaciones

\footnotetext{
${ }^{31}$ Ver la Opinion No 25 "Ethics of Synthetic Biology" (2009) del European Group on Ethics in Science and New Technologies (EGE) de la Comisión Europea del que tuve el honor de ser miembro durante los últimos 10 años: http://ec.europa.eu/european_group_ethics/avis/index_en.htm

${ }^{32}$ Ver http://www.capurro.de/paraiba.html
} 
posteriores. $^{33}$ La filosofía de la información de Luciano Floridi, por tomar un ejemplo, se basa en el concepto platónico de forma que va más allá de una filosofía computacional aunque a menudo el término 'infosphere' utilizado por Floridi parece restringirse a la esfera digital o a Internet mientras que otras veces se refiere a todo tipo de formas (digitales o no) y de 'in-formaciones' desde el átomo hasta el universo. Creo que es esta una visión metafísica o, para decirlo en forma polémica y Nietzscheana, un "platonismo para el pueblo" ("Christentum ist Platonismus fürs Volk"). Ya la filosofía escolástica distinguía entre 'creatio' e 'informatio' para mostrar que luego de la creación tienen lugar diversos procesos 'informacionales' lo que posteriormente Charles Darwin concebirá como evolución de las especies. Creo, también, que la técnica digital no nos lleva necesariamente a otra tesis de tipo metafísico pensando que los entes están compuestos de 0 y 1 digitales como lo postularía un pitagoreismo digital.

Mi tesis sobre la 'ontología digital' es de orden epistemológico. De ninguna manera preconizo que la comprensión digital de los entes sea la verdadera sino una perspectiva posible, pero sí característica de nuestra ciencia y vida actual, aunque sería un grave error pensar que esta predominancia es igual en todas las culturas y mucho menos que ella es entendida como tal por la mayoría de los seres humanos. Es más bien el 'espíritu de nuestro tiempo' ("Zeitgeist") interpretado filosóficamente. Algo semejante a la interpretación de la realidad desde el punto de vista del materialismo dialéctico en el siglo XIX hasta mediados del siglo XX con todas las consecuencias sociales, culturales y políticas que este tipo de cambio de horizonte o de paradigma trae consigo y que recién comienza a vislumbrarse en el caso de la ontología digital. (61:30)

Basta pensar en las transformaciones del sistema político como las vivimos en las últimas elecciones en los Estados Unidos y como seguramente tendrán lugar en Brasil próximamente. Es el paso de una mediocracia televisiva y jerárquica a una interactiva y horizontal con todas las esperanzas, incertidumbres, peligros y opciones que trae consigo esta transformación en el concepto de democracia y de sus realidades históricas concretas. Es difícil ver lo que es y puede ser. Lo podemos ir haciendo sólo poco a poco, buscando - también académicamente en el espacio de pensamiento que abre la ética - opciones de vida que hasta ahora no eran ni posibles ni a menudo imaginables y con respecto a las cuales tendremos que cambiar tal vez normas y valores morales y culturales tradicionales. La ética de la información puede autocomprenderse como un catalizador de este complejo proceso social. Un ejemplo actual y concreto de estas transformaciones y tensiones es la discusión en torno a Google en China. En este contexto es interesante destacar que el 28-29 de octubre de 2010 tendrá lugar en la Universidad de Renmin (Beijing) la "Primera conferencia internacional sobre la ética de la información en China". 34

\footnotetext{
${ }^{33}$ Ver http://www.capurro.de/info.html y http://www.capurro.de/leon.pdf

${ }^{34} \mathrm{Ver}$ http://www.wongpakhang.com/chineseinfoethics/
} 
Pergunta:

Teve um comentário seu do que você falo ontem na palestra a os fundos de privacidade, algo que já o Castelles falava de isso em 1999 ou 98 ... com a ... da internet a idéia de privacidade se há ido ao espaço, acabo, a medida de que você ligava um computador, falava no celular e ontem você toco isso na sua palestra e eu queria te perguntar, com relação a esta questão da google na China, Como e que você esta vendo isto da aqui para o frente, essa idéia de privacidade que e um valor ao meu ver que era bastante caro a nós ocidentais...com essa digitalização democratização da informação, como e que você veria essa questão de privacidade.

El tema de la privacidad es muy complejo, y depende de cómo se concibe el otro concepto que es el de público. La diferencia - o el 'código' ("code") como la llamaría Luhmann - de público/privado se puede observar en distintas culturas y sociedades en diferentes épocas y en relación a diferentes medios. Piensen, por ejemplo, en la forma en que se vivía esta diferencia en Brasil cuando llegó la familia real portuguesa y lo que se puede observar actualmente en este país. Creo que toda sociedad humana se basa, aunque no únicamente, en esta diferencia. Ella tiene tal vez sus orígenes en la evolución y en la necesidad de protección. Nuestra comprensión de los intereses y objetivos de otros seres humanos es siempre limitada.

La pregunta ¿hasta qué punto puede confiarse en otra persona? tiene su credibilidad subjetiva en la experiencia personal. ¿Hasta qué punto puedo confiar en mí mismo, en mis procesos orgánicos y psíquicos, mis promesas y compromisos, mis deseos, valores y creencias? El autoconocimiento siempre es limitado, como lo indicaba la inscripción en el frontispicio del templo de Delfos "Conócete a tí mismo" es decir, comienza por reconocer que no te conoces ni que puedes conocerte completamente. En esto se fundamenta también el escepticismo socrático. La biología y en particular la investigación cerebral nos muestran hasta qué punto los procesos biológicos no sólo tienen una dinámica que escapa a nuestra volutad sino que la condicionan en forma compleja sin que dicho condicionamiento tenga que interpretarse necesariamente como un determinismo aunque sí como una condición necesaria aunque no suficiente de la conducta humana. Esto vale también para los condicionamientos basados en las relaciones sociales y en el ser-en-elmundo en general. Somos lo que somos con y a través de los otros. Somos, por expresarlo heideggerianamente, en-el-mundo-con-otros y luego pensamos. El ser social fundamenta al pensar (también social) como lo preconizaba Karl Marx (68:51).

Pero además de la diferencia público/privado existe también la diferencia público/secreto. ${ }^{35}$ El concepto actual de privacidad está relacionado en Occidente en particular a las costumbres de la sociedad burguesa del siglo XIX y al recinto de las "cuatro paredes" a las que alude Hannah Arendt en su obra "Vita Activa". Las diferencias público/privado y

\footnotetext{
${ }^{35}$ Ver http://www.capurro.de/secreto.html
} 
público/secreto se pueden observar en diversas sociedades y situaciones históricas, particularmente en situaciones límite como en el caso de dictaduras en las que el intento de eliminar toda privacidad se basa paradójicamente en un sistema paranoico de servicios secretos. Las sociedades africanas no menos que las del Lejano Oriente tienen diversos conceptos y prácticas de privacidad que se diferencian, también en su fundamentación filosófica, de las de las sociedades occidentales. La red digital parece imponer un imperativo moral "icomunica todo a todos!" incluso en forma agudizada "ihazlo todo el tiempo, en todo lugar y sin límites!" Las consecuencias de este imperativo en el ámbito de la salud psíquica y física son cada vez más acuciantes, sin que tengamos todavía una visión de conjunto de los fenómenos patológicos derivados de la sociedad de la información. ${ }^{36}$

$$
(1: 12: 00)
$$

Nuestra época está fascinada por la comunicación y la artificialidad a diferencia por ejemplo del siglo XIX y XX donde todo giraba tanto a nivel social como filosófico en torno a la historia y la naturaleza. En Brasil, con una naturaleza tan apabullante, me da la impresión que se produce un enlace entre lo artificial (digital), lo natural y la comunicación o por lo menos que este enlace se ve como algo clave para diversas formas de estructurar la vida diaria de los brasileros, sus identidades, relaciones sociales, procesos de producción, espacios y tiempos de descanso y diversión etc. El Brasil está transformándose en un país tropical digital. Naturalmente que esto lleva a redifinir las líneas divisorias entre las diferencias a las que aludía anteriormente y con ellas también a redefinir conceptos morales y legales, percepciones en los límites morales del lenguaje y de las imágenes así como las razones y las situaciones desde las que dichos límites son cuestionados. Estas pueden tener que ver con diversas formas de concebir la libertad, la comunidad, el respeto, la transparencia, la vergüenza, la vulgaridad, el desinterés, la calumnia, el odio... en una palabra todo el cosmos de la (in-)moralidad humana. Y todo esto se vuelve más complejo no sólo dentro de una sociedad multiétnica como la brasilera y muchas otras sociedades actuales, sino también porque ellas se abren e influencian mutuamente en procesos digitales y migracionales globales que no pueden ser regulados de forma semejante a lo que se hacía con los sistemas jerárquicos de distribución de mensajes del siglo XX los cuales además perduran y se hibridizan con la red digital interactiva así como con estructuras materiales de vida especialmente en las megacities. La ética de la información abre un espacio para debatir estos temas y se diferencia por ello de la moralidad vigente que es su objeto de estudio.

Pergunta:

Professor Rafael, estamos nas ciências da informação a seccion digital é um objeto das pesquisas na ... de esse incentivo da tecnologia se

\footnotetext{
${ }^{36}$ Ver http://www.fundacionmhm.org/www_humanitas_es_numero47/revista.html
} 
acoplando não sei, a dinâmica própria de produção do conhecimento Como o senhor vê a ciência da informação nesse esenario e que papel que ela pode assumir.porque no contexto de ... um papel ... mais como a gente pode entrar em essa própria dinâmica de fazer sentir e pensar a própria tecnologia ...que é uma discussão que vem muito da ciência e tecnologia que também se esta dando essa temática Como você acha que a ciência da informação se coloca nesse campo?(76:37)

Mi portugués es limitado. Algo entendí del problema pero usted me corregirá, el problema de cómo se ubica la producción del conocimiento científico en el sistema social ¿Es eso lo que está preguntando?

É mais na pratica, na pratica cientifica desde o ponto de vista do pesquisador.

\section{¿Del investigador cientifico?} tecnologia

Cientifico, que hoje o saber cientifico se modifica perante ...

Ok.

A gente sempre toca o objeto a ...e o digital ...mais quando ele passa a fazer parte da forma em que a gente constrói o conhecimento, como a gente constrói a própria pesquisa, como a ciência da informação .

Los científicos actualmente producen, distribuyen y comparten sus investigaciones en un sistema digital el cual es objeto de la ciencia de la información. Un tema clave en el plano ético y legal es el derecho de autor que tiene sus raíces históricas en Occidente en el Estatuto de la Reina Ana en 1710. Tanto el derecho de autor como el sistema de patentes fueron creados con la finalidad de evitar el secreto o sea de promover la publicidad haciendo que algo sea al mismo tiempo público y protegido. La ciencia funciona en base a este principio de publicidad y no-censura que permite un control crítico mutuo como bien lo preconizaron los filósofos de la Ilustración y el Racionalismo Crítico. Una alternativa aparente - puesto que no es generalizable - es el secreto, como en el caso de Microsoft o Google. Esto nos muestra una paradoja de la sociedad de la información que cuestiona el modelo clásico de propiedad intelectual con modelos como open source, open access, free software, GNU General Public Licence y copyleft que constituyen verdaderas alternativas al régimen del copyright. Están en juego aquí no sólo intereses económicos de los global players modernos como son las casas editoriales, las grandes cadenas televisivas, los distribuidores de producciones fílmicas y musicales quienes no cesan de pregonar que sus intereses coinciden con los de los productores cuando es evidente que en muchos casos el negocio lo hacen los mediadores y no los productores. Esto ha llevado a que los científicos creen redes de comunicación y distribución al margen de los canales clásicos, en especial de los productos impresos. Quienen se aprovechan de esto son en especial los científicos y usuarios de los países en vías de 
desarrollo. Pero es también claro que los sistemas de control clásicos y el prestigio de los distribuidores siguen siendo parte de la comunicación científica con sus criterios y centros de poder de selección y promoción profesional. Vivimos, en otras palabras, en sistemas híbridos que deberían ser analizados y evaluados, también éticamente, por la ciencia de la información.

$(1: 28: 20)(90: 52)$

La pregunta es si hay algún paradigma preponderante en las ciencias de la información la primera frase es esta, "¿usted cree en la existencia de un paradigma post moderno o esto es solamente una situación provisoria, o estamos viviendo un pasaje de una situación paradigmática hacia otra?"

$\mathrm{Si}$, creo que con Internet se produce un cambio paradigmático en la ciencia de la información con respecto a como era concebida en la década del 70, como lo indiqué ya anteriormente. Se podría cuestionar la radicalidad de dicho cambio si uno tiene en cuenta que los métodos del information retrieval, incluyendo los estudios de los usuarios que estaban circunscritos originariamente a comunidades científicas, son ahora la base de procesos sociales generalizados y aplicados en todas las áreas de la vida pública. ¿Hasta qué punto este cambio cuantitativo, que es también un cambio en el contenido y el objetivo de la comunicación, significa un cambio cualitativo y paradigmático en el sentido de Thomas Kuhn? Si se observa que dichos procesos, sus instituciones, métodos y sobre todo su impacto a nivel local y global es difícilmente comparable a las bases de datos bibliográficas de la década del 70 , se puede hablar de un cambio paradigmático. Es tal vez por esto que en este nuevo paradigma repercuten con más intensidad las corrientes de pensamiento filosófico y sociológico mencionadas anteriormente. Las prácticas generalizadas de las sociedades de la información transforman los esquemas teóricos de la ciencia de la información tradicional.

Algunos colegas, como Bernd Frohmann, siguen caminos abiertos por Michael Buckland, retomando el concepto de documentación. Otros grupos, como el de "Foundations of Information Science" (FIS) conectado al proyecto BITrum que dirije José María Díaz Nafría ${ }^{37}$ están interesados en una visión interdisciplinar y preconizan una nueva ciencia de la información. ${ }^{38}$ Chaim Zins hizo una encuesta titulada "Knowledge Map of Information Science" que ofrece una vista de conjunto sobre diversas teorías de la ciencia de la información. ${ }^{39}(1: 32: 57)$ En este contexto es importante observar que las divisiones u oposiciones entre informática, ciencia de la información, biblioteconomía, archivística y museología a las que aludía al comienzo, van perdiendo cada vez más su relevancia en la medida en que la sociedad de la información se vuelve consciente de la interrelación de estos sistemas y de sus soportes mediáticos que

\footnotetext{
${ }^{37}$ Ver http://bitrum.unileon.es

${ }^{38} \mathrm{Ver}$ http://fis.icts.sbg.ac.at/

${ }^{39}$ Ver http://www.success.co.il/is/index.html
} 
dependen en mayor o menor grado de la técnica digital. Tanto las bibliotecas como los archivos son un caso muy claro de relevancia social y política en relación a las dimensiones de publicidad, secreto, inclusión social y transparencia sobre todo en el marco de sociedades democráticas. La obra del catedrático de derecho Lawrence Lessig muestra claramente la importancia de las estructuras comunicacionales basadas en la tecnología digital, las cuales condicionan las normas jurídicas y morales de la sociedad de la información, y en particular diversas formas de inclusión 0 exclusión. (1:36:50)

Las sociedades del siglo XXI giran en torno a preguntas como ¿cuáles son los nuevos sistemas de poder que se están estableciendo?, ¿con qué consecuencias? y ¿con qué medios? ¿Cuáles son las tecnologías, medios e instituciones que posibilitan sociedades informacionales inclusivas como lo preconiza la Cumbre Mundial de la Sociedad de la Información? Pensemos en el aporte invalorable de las bibliotecas públicas para sociedades en las que el libro era una barrera económica así como lo eran las bibliotecas reales y las de los conventos hasta la Revolución Francesa. Si creamos bibliotecas públicas digitales es evidente que tenemos que faciliar su acceso público generalizado basado también en las estructuras bibliotecarias. Pero debemos pensar también en la transformación de una cultura del libro, o, mas en general, del texto y de la lectura, a una de la imágenes. ¿Hasta que punto podemos hablar de una crisis de la lectura en las instituciones educacionales actuales? ¿Tiene esto que ver con el predominio de Internet y los nuevos medios como lo creen algunos críticos pesimistas y conservadores? Estas son preguntas que la nueva ciencia de la información tiene que investigar tanto a nivel filosófico como empírico.

Temos varias perguntas. Agora o Pedro.

Professor, a minha pergunta e sobre a cultura, nos sabemos que o sistema internacional de direitos humanos ele e feito e baseado nas sociedades modernas ocidentais especialmente a européia, e por outro lado todos os paises do mundo sofrem a pressão muito grande para ratificar... dos direitos humanos e alguns paises não estão conseguindo implementar de forma completa essas convenciones justamente porque vão de outra à cultura vigente, ...

Una pregunta difícil porque, como Ud. lo indica, los derechos humanos están basados, filosóficamente, en la cultura occidental. Como ustedes saben, la señora Eleanor Roosevelt fue la gran promotora de los derechos humanos. Se pueden leer los debates que hubo durante muchos meses de su gestación. ${ }^{40}$ Estos debaten muestran que este documento fue el fruto de un difícil diálogo ético y político que fue aprobado en 1948 por las Naciones Unidas. Aunque no tiene una fuerza legal en los estados que lo firman, tiene si un poder diplomático así como una gran influencia en otros tratados internacionales y en constituciones nacionales. Pensemos, por ejemplo, en la "Declaración de Principios" de la Cumbre Mundial de la

\footnotetext{
${ }^{40}$ Ver http://www.udhr.org/history/default.htm
} 
Sociedad de la Información de $2003^{41}$ o en el "Código de Ética para la Sociedad de la Información" elaborado actualmente por la UNESCO en base a conferencias y declaraciones regionales lo que muestra la tensión entre principios o valores universales y tradiciones culturales locales. ${ }^{42}$

Recordemos los debates en la Cumbre Mundial en torno a un derecho universal a la comunicación que cuestionaría las estructuras jerárquicas de poder en ciertos estados así como también los debates académicos en torno a la ética intercultural de la información a los que aludía al comienzo al referirme a la conferencia del ICIE en Karlsruhe en 2004. Todo código legal o moral necesita ser interpretado y aplicado como lo vió claramente la hermenéutica gadameriana. Es imprescindible entonces el abrir un diálogo a nivel académico y político en el que se piensen los principios y valores universales en relación a situaciones concretas para ver de qué modo se relacionan con la vida y los intereses de las personas y las comunidades concretas. Es importante además considerar que los derechos humanos no deberían concebirse en forma antropocéntrica es decir desligados de principios y valores relacionados a los otros seres vivientes y a la naturaleza en general. Toda explicitación, en especial en forma de una ley o de un derecho, pone de manifiesto una tensión en la sociedad que necesita problematizar algo que se daba por sobreentendido y que entra en crisis. Esto lo muestra por ejemplo Michel Foucault con relación al discurso y la prácticas sexuales y a las instituciones psiquiátricas del siglo XIX y XX. El "Habeas Corpus" inglés se refleja actualmente en lo que se puede llamar "Habeas Data" es decir en las leyes de protección de la privacidad de datos personales digitales en la sociedad de la información. ${ }^{43}(1: 56: 51)$

Eu gostaria de saber Como você vê a possibilidade de que os ... das pessoas modificarem a sua própria identidade, de ali que ela as pessoas e as informações de ela própria serem modificadas por própria vontade o criando um avatar ou se fazendo passar por uma outra pessoa. Agora como nos Estados unidos de infiltrar agentes nas redes sociais para descobrir ... ate onde essa identidade pode ser alterada por outras pessoas de forma maliciosa se faze passar por outra pessoa então e a declaração entre identidade e a sua própria informação o eu já... no ambiente digital.

El tema de identidad es un tema clave para las nuevas generaciones que construyen identidades en la red. ¿Quién soy cuando estoy en la red? Pensemos que la separación entre una vida diaria dentro y fuera de la red es cada vez menos relevante ya que nos vamos transformando en individuos y sociedades híbridas. Esto significa que las identidades físicas y las digitales están íntimamente entrelazadas. Lo que sucede en la red

\footnotetext{
${ }^{41}$ Ver http://www.itu.int/wsis/docs/geneva/official/dop.html

${ }^{42}$ Ver http://portal.unesco.org/ci/en/ev.phpURL ID $=24935 \&$ URL DO=DO TOPIC\&URL SECTION=201.html)

${ }^{43}$ Ver la Opinion No. 20 "Ethical Aspects of ICT Implants in the Human Body"(2005) del European Group on Ethics in Science and New Technologies (EGE) de la Comisión Europea:

http://ec.europa.eu/european_group_ethics/avis/index_en.htm
} 
puede tener repercusiones casí inmediatas en la vida real sobre todo con relación a todo tipo de manipulaciones y usos de dichos datos para objetivos no previstos o no aprobados por los sujetos mismos. Las "cuatro paredes" a las que se refería Hannah Arendt no son suficientes para proteger al individuo no sólo por estar perforadas digitalmente sino también porque gran parte de los conocimientos y datos de los individuos y organismos laborales y políticos se encuentran almacenados en los laptops, iphones y servidores - en el futuro en 'nubes' de servidores - de tal manera que individuos y grupos externalizan en ellos gran parte de la información contenida en la memoria biológica o en otros medios no digitales. Todo esto crea problemas éticos y legales de gran envergadura que son vistos y evaluados diversamente de acuerdo a diversas situaciones, tradiciones culturales, intereses económicos y sistemas políticos.

El professor Makoto Nakada de la Universidad de Tsukuba (Japón) hace estudios empíricos de ética de la información por ejemplo entre Japón, Korea y China. ${ }^{44}$ Uno de ellos se refiere, por ejemplo, a la forma en que estudiantes de Japón y Korea perciben las imágenes personales en Facebook, siendo así que en Korea esto no crea ningún problema pero sí en el Japón. Creo que estos estudios empíricos comparados son de gran importancia no sólo para relacionar aproximaciones filosóficas abstractas con la realidad actual sino también para concebir una nueva ciencia de la información en la que dichos análisis ético-sociales deberían constituir un núcleo importante de su autocomprensión.

Alguém mas tem uma pergunta? A não tem mais uma desculpa. Não da para ler mais uma esta é a ultima.

A pergunta é de Rodrigo Moreno, A dialética materialista e um bom caminho para abordar a ética na internet quando a web esta cada vez mais dominada pelo mercado e pelos valores do capital?

Sí, hay colegas que muy afines a la dialéctica materialista en la que se basan para interpretar los conflictos digitales de las sociedades de la información del siglo XXI. Pienso, por ejemplo, en los austríacos Christian Fuchs y Wolfgang Hofkirchner, editores de la revista triple C (Cognition Communication Cooperation). ${ }^{45}$

Creo que este marco metodológico conectado a lo que Ortega y Gasset llamaría "el tema de nuestro tiempo" es muy importante porque permite identificar las transformaciones sociales en términos de trabajo, capital y poder político.(2:05:13) Karl Marx vió claramente no sólo la importancia social de los instrumentos y procesos de producción sino también los de la comunicación. Creo que las grandes transformaciones de las sociedades europeas y no-europeas de posguerra no pueden

\footnotetext{
${ }^{44}$ Ver http://www.infomedia-ethics.org/

${ }^{45}$ Ver http://www.triple-c.at/index.php/tripleC/about
} 
interpretarse adecuadamente si no se las percibe desde la perspectiva de los cambios rápidos y fundamentales de los sistemas de comunicación tanto de los medios de comunicación de masas como de los medios interactivos digitales. Pensemos no sólo en World Wide Web, el correo electrónico, así como blogs y twitter sino también en los global players de la industria de hardware y software, en la importancia que esta tiene en países emergentes como China, India y Brasil y en los conflictos dentro y entre las sociedades digitalizadas del siglo XXI con respecto a lo que se suele llamar la brecha digital. ¿En qué medida la crisis económica mundial tiene causas en el sistema comunicacional digital? ¿Cómo está organizado el capitalismo internacional en el siglo XXI en base a las redes digitales? ¿Cuál es la relación entre capital e información en la era digital tanto a nivel conceptual como práctico-político?

Bom nos vamos a encerrar com a sessão de perguntas e gostaria de agradecer a presença de todos: a presença de todos de alunos de graduação e pós-graduação que estiveram aqui, aos colegas, os professores, a nossa diretora Virginia, a os colegas aqui da post e ao professor Carlos que tem dado uma ajuda muito grande aí na vinda do professor Capurro e agradecer ao professor pela sua contribuição e dividir com a gente o seu conhecimento professor. Obrigado.

Muchas gracias. Ha sido un placer para mi estar con ustedes. Quedo a las órdenes para lo que pueda serles útil. 